\title{
Internal Waves and Mixing in the Aegean Sea
}

\author{
Michael C. Gregg \\ Applied Physics Laboratory, University of Washington \\ 1013 NE $40^{\text {th }}$ St. \\ Seattle, WA 98105-6698
}

phone: (206) 543-1353 fax: (206) 543-6785 email: gregg@apl.washington.edu

Matthew Alford

Applied Physics Laboratory, University of Washington

1013 NE $40^{\text {th }}$ St.

Seattle, WA 98105-6698

phone: (206) 221-3257 fax: (206) 543-6785 email: malford@apl.washington.edu,

Jack B. Miller

Applied Physics Laboratory, University of Washington

$1013 \mathrm{NE} 40^{\text {th }}$ St.

Seattle, WA 98105-6698

phone: (206) 543-9959 fax: (206) 543-6785 email: miller@apl.washington.edu

Grant Number: N00014-04-1-0238

\section{LONG-TERM GOALS}

To identify the major processes producing mixing in the upper ocean and to understand their dynamics sufficiently well to permit accurate parameterization of mixing for use in numerical models.

\section{OBJECTIVES}

This project was designed to understand how the very rugged and irregular bathymetry in the Aegean Sea modifies the internal wave field and the mixing it produces. Because tides are weak throughout the Mediterranean, mixing produced by internal waves should stand out, unlike the situation on the U.S. coasts, where tidal currents generate a significant fraction of the mixing. Going to a place where one of the two major processes is weak should allow us to understand better the role of internal waves, e.g., how much of the mixing observed close to sloping bottoms results from scattering of internal waves?

\section{APPROACH}

We used moorings and intensive microstructure and towed measurements to examine small-scale fields on the southern slope of the Cycladic Plateau, just west of Santorini in the central Agean (Fig. 1). Colleagues at the Hellenic Centre for Marine Research (HCMR) had previously obtained highresolution bathymetry of the site, and fishing was not intense in the region. These provided excellent records of internal waves and mixing during the transition from summer to winter conditions in the Aegean. Tides are weak in the Aegean because the Mediterranean basin is much to small to resonate 


\section{Report Documentation Page}

Form Approved

OMB No. 0704-0188

Public reporting burden for the collection of information is estimated to average 1 hour per response, including the time for reviewing instructions, searching existing data sources, gathering and maintaining the data needed, and completing and reviewing the collection of information. Send comments regarding this burden estimate or any other aspect of this collection of information,

including suggestions for reducing this burden, to Washington Headquarters Services, Directorate for Information Operations and Reports, 1215 Jefferson Davis Highway, Suite 1204, Arlington

VA 22202-4302. Respondents should be aware that notwithstanding any other provision of law, no person shall be subject to a penalty for failing to comply with a collection of information if it

does not display a currently valid OMB control number.

1. REPORT DATE

30 SEP 2007

4. TITLE AND SUBTITLE

Internal Waves And Mixing In The Aegean Sea

6. $\operatorname{AUTHOR}(\mathrm{S})$

7. PERFORMING ORGANIZATION NAME(S) AND ADDRESS(ES)

University of Washington,Applied Physics Laboratory,1013 NE 40th St,Seattle,WA,98105

9. SPONSORING/MONITORING AGENCY NAME(S) AND ADDRESS(ES)

\section{REPORT TYPE}

Annual

00-00-2007 to 00-00-2007

5a. CONTRACT NUMBER
5b. GRANT NUMBER
5c. PROGRAM ELEMENT NUMBER
5d. PROJECT NUMBER
5e. TASK NUMBER
5f. WORK UNIT NUMBER
8. PERFORMING ORGANIZATION
REPORT NUMBER
10. SPONSOR/MONITOR'S ACRONYM(S)
11. SPONSOR/MONITOR'S REPORT
NUMBER(S)

12. DISTRIBUTION/AVAILABILITY STATEMENT

Approved for public release; distribution unlimited

13. SUPPLEMENTARY NOTES

code 1 only

14. ABSTRACT

15. SUBJECT TERMS

16. SECURITY CLASSIFICATION OF:

a. REPORT

unclassified b. ABSTRACT unclassified c. THIS PAGE unclassified
17. LIMITATION OF ABSTRACT

Same as Report (SAR)

\begin{tabular}{l|l}
$\begin{array}{l}\text { 18. NUMBER } \\
\text { OF PAGES } \\
\mathbf{6}\end{array}$ & 19a. NAME OF \\
& RESPONSIBLE PERSON \\
&
\end{tabular}


with tidal forcing. During our intensive measurement HCMR colleagues conducted a hydrographic survey around us from their ship, the R/V Aegaeo.

\section{WORK COMPLETED}

Most of the analysis has been done for some time, but completion and publication has been delayed by the need to understand and document the noise level of our dissipation measurements. Below the shallow pycnocline stratification in the Aegean rapidly drops to abyssal levels. As a result, even very low dissipation rates correspond to large diapycnal diffusivities. This effort is nearly completed.

\section{RESULTS}

The work area (Fig. 1) was selected for its steep bathymetry and low level of fishing. Most of our data were taken with Advanced Microstructure Profilers (AMPs). Several grids were used, some up and down slope, others along slope, and another as radial lines crossing the small seamount centered at $36.45 \mathrm{~N}, 25.1 \mathrm{~W}$. Time series of current and stratification from the moorings as well as a synoptic survey by Greek colleagues provide background for interpreting the turbulence.
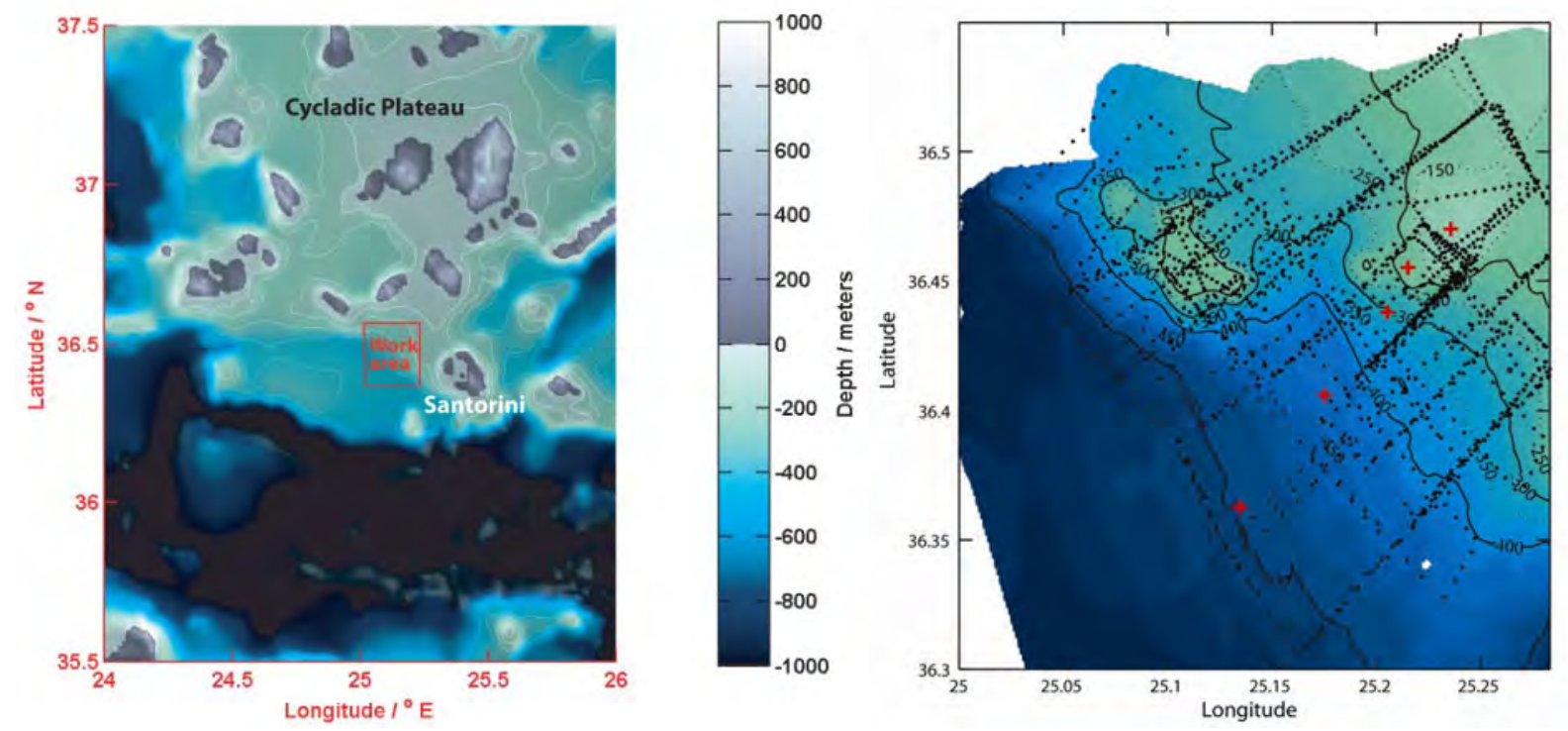

Figure 1. Bathymetry of the south side of the Cycladic Plateau in the Aegean Sea (left) and (right) positions of AMP drops (black dots) and moorings (red crosses) in the work area. Isobaths are

labed with meters. From north to south, the moorings were a $300 \mathrm{kHz}$ WorkHorse set on the bottom at 110 m, Moored Profilers at 180 m, $300 \mathrm{~m}$ and 420 m, and a LongRanger $75 \mathrm{kHz}$ at $500 \mathrm{~m}$.

Begun on 27 October 2004, the turbulence measurements fortuitously caught the very rapid transition from summer to winter conditions in the Aegean. Cold air and increased winds deepened the surface mixed layer from 40 to $70 \mathrm{~m}$ while we were in the area (Fig. 2) and provided a changing background for the turbulence. 


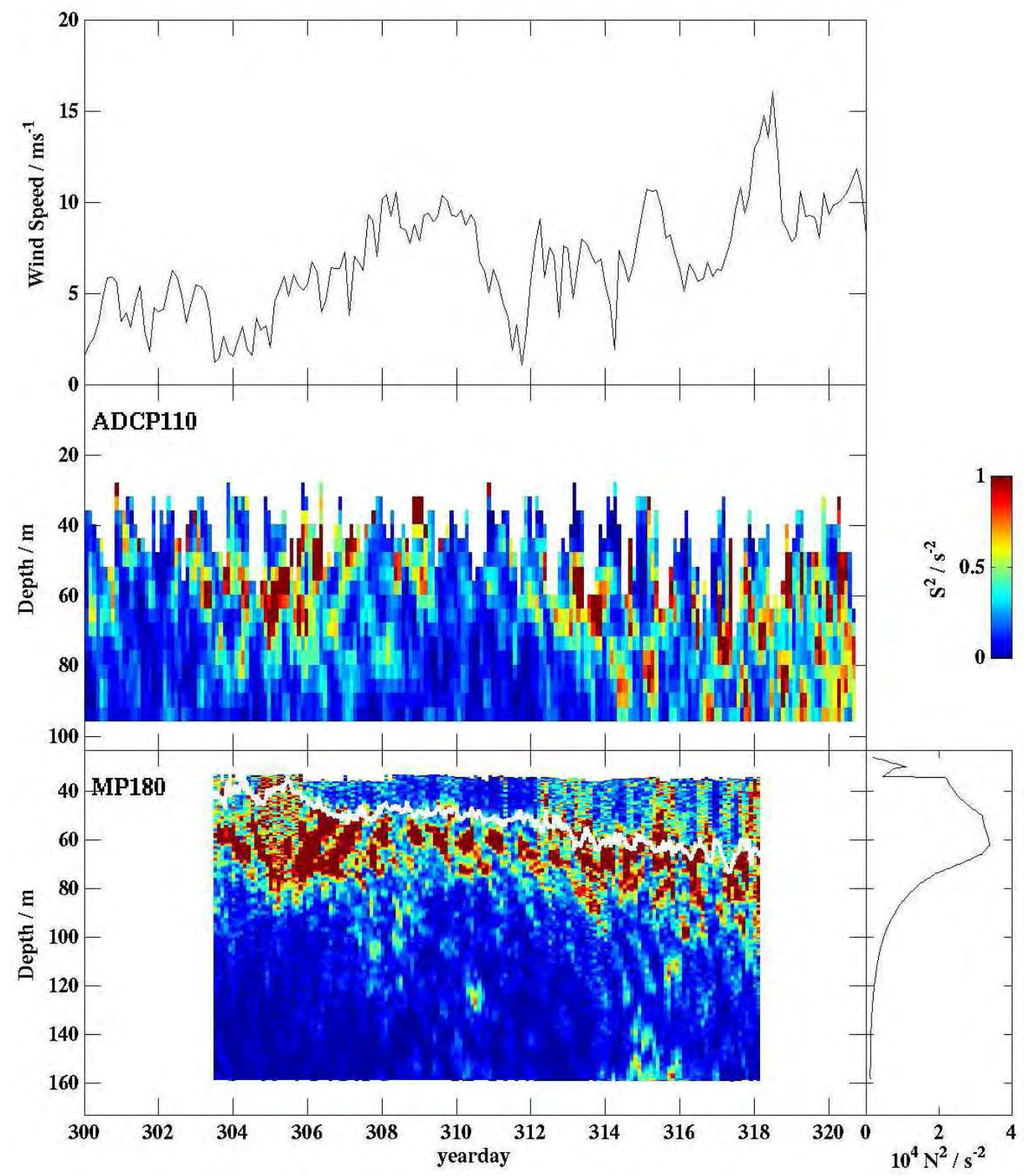

Figure 2. Top) wind speed, Middle) shear-squared measured with the WorkHorse $300 \mathrm{kHz}$ ADCP on the bottom at $110 \mathrm{~m}$, and Bottom) shear-squared and stratification $\left(\mathrm{N}^{2}\right)$ measured with the Moored Profiler moored at $180 \mathrm{~m}$. The observations caught the rapid transition from summer to winter and the accompanying increase in shear-squared at the base of the mixed layer (white line in MP180 panel) that deepened the layer. The ragged upper boundary of the $300 \mathrm{kHz}$ record resulted from the daily migration of the scattering layer.

Initially, dissipation rates dropped rapidly with depth below the pycnocline beneath the mixed layer, except around a small seamount on the continental slope at the west end of the work area and in a density current traveling along isobaths just upslope from the seamount (Fig. 3). Although dissipation rates were modest in these two regions, $10^{-9}$ to $10^{-8} \mathrm{~W} / \mathrm{kg}$, owing to the weak stratification the diapycnal diffusivities were fairly large, $10^{-4}$ to $10^{-3} \mathrm{~m}^{2} / \mathrm{s}$. Elsewhere below the pycnocline dissipation 
rates were close to $10^{-10} \mathrm{~W} / \mathrm{kg}$, the level we have long defined as our noise level. Even these, however, correspond to diffusivities close to $10^{-5} \mathrm{~m}^{2} / \mathrm{s}$, the background level in the open-ocean thermocline. This in turn has forced us to examine how we define our noise levels, a job far more difficult than expected but nearly complete.

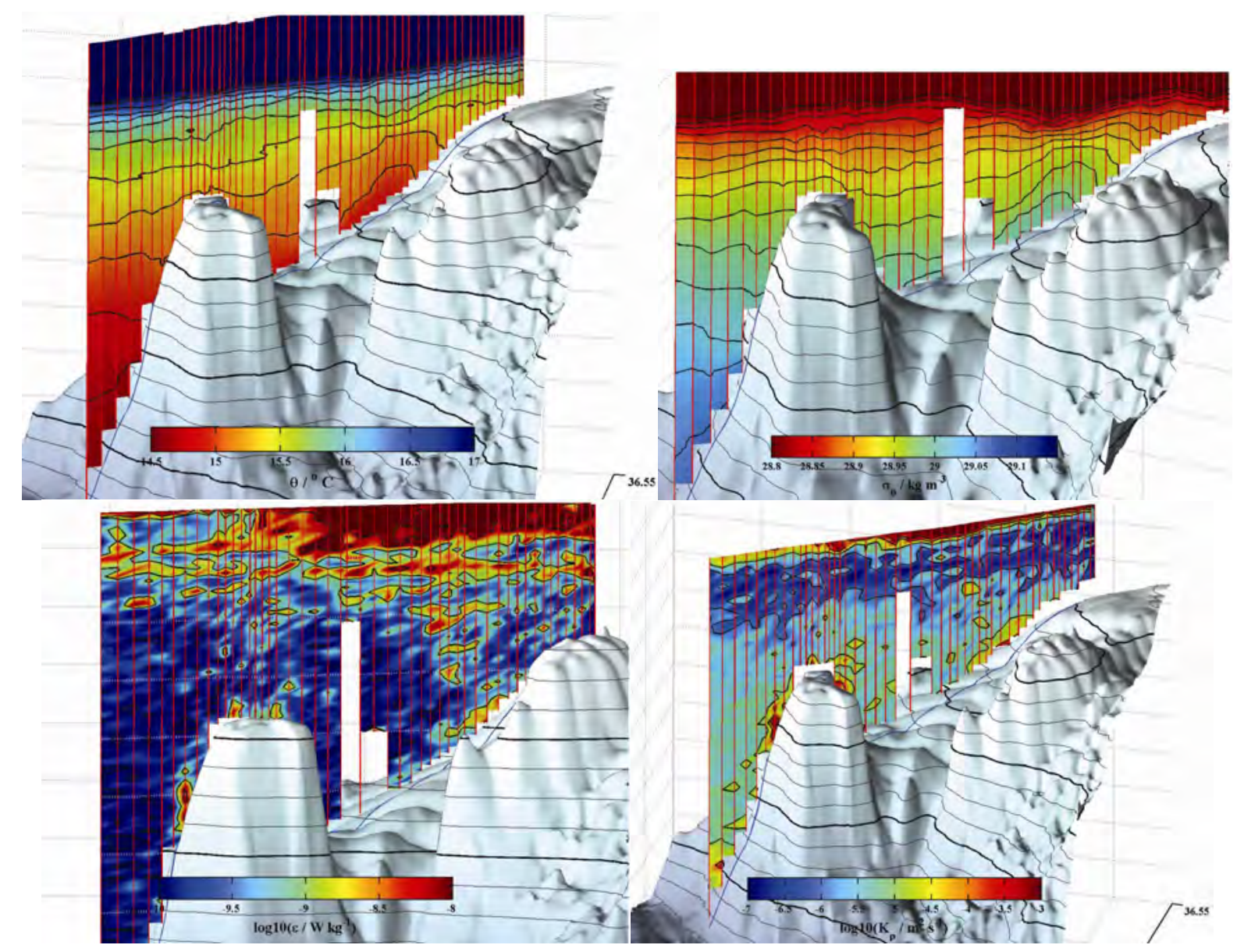

Figure 3. AMP section downslope and across a small seamount. Upper left) temperature, Upper right) Potential density, Lower left) Logarithm of the dissipation rate, and Lower right) Logarithm of diapycnal diffusivity. Vertical red lines are position of AMP profiles. Isobath contours are at 25 $m$ intervals with hundreds made darker. Temperature and density contours reveal a density current flowing along the isobaths. It is one of the few places with strong diffusivity.

Shear-squared below the pycnocline increased in response to the rising winds, as seen in the MP180 panel of Figure 2. The effect on diapycnal diffusivity is shown in Figure 4 which compares two AMP lines along the same cross-slope line. Within about $100 \mathrm{~m}$ of the slope dissipation rates during yday 314 were about ten times those during yday 302. Once we have final dissipation rate, we will attempt to determine how much of the increase resulted from downward propagation of shear and how much from scattering from the sloping bottom. 

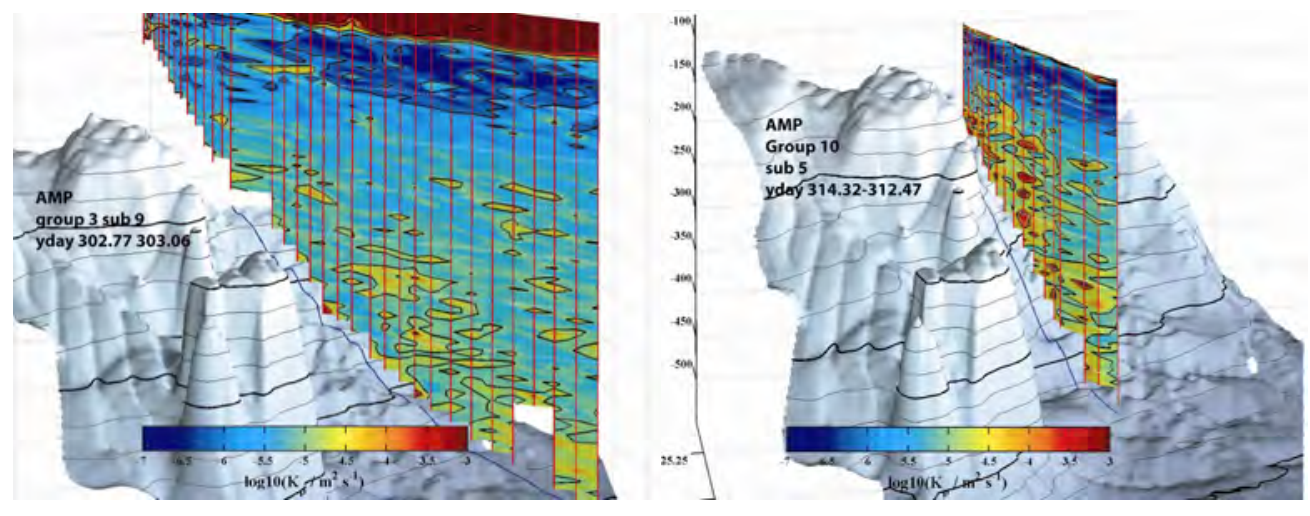

Figure 4. Increase in the logarithm of diapycnal diffusivity along the downslope section between yday 302.9 (left) and yday 314.4 (right), apparently in response to the increase in wind speed (Fig. 1). 